\title{
Papers
}

\section{What do patients receiving palliative care for cancer and their families want to be told? A Canadian and Australian qualitative study}

\author{
Peter Kirk, Ingrid Kirk, Linda J Kristjanson
}

\begin{abstract}
Objective To obtain feedback from patients receiving palliative care and their relatives from various ethnic backgrounds about their experiences of the disclosure process and their satisfaction with information sharing during the illness.

Design A qualitative study with semistructured single interviews.

Setting Perth, Western Australia, and Winnipeg, Manitoba, Canada.

Participants 72 participants registered with palliative care: 21 patient-family dyads in Perth and 14 dyads and 2 patients in Winnipeg.

Results Participants described their experiences in great detail. The analysis indicates that in information sharing the process is as important as the content. The timing, management, and delivery of information and perceived attitude of practitioners were critical to the process. This applied to information interactions at all stages of the illness. Main content areas mentioned related to prognosis and hope. Hope can be conveyed in different ways. Secondary information from various sources is accessed and synthesised with the primary information. All patients, regardless of origin, wanted information about their illness and wanted it fully shared with relatives. Almost all patients requested prognostic information, and all family members respected their wishes. Information was perceived as important for patient-family communication. Information needs of patient and family changed and diverged as illness progressed, and communication between them became less verbally explicit.

Conclusions Information delivery for patients needs to be individualised with particular attention to process at all stages of illness. Patients and families use secondary sources of information to complement and verify information given by health carers.
\end{abstract}

\section{Introduction}

The provision of information to terminally ill patients and their families within the context of obligations for full disclosure can cause uncertainty. Research on attitudes and beliefs of health professionals has shown some of the potential barriers and problems associated with information sharing. ${ }^{1}$ In some cultures physicians or families, or both, deem full disclosure to be prejudicial to the patient. ${ }^{2}$ The need for specific attention to cultural assumptions that may affect communication has been high-

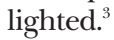

Breaking bad news is a complex communication task, affecting the patient's comprehension, satisfaction with care, and level of hopefulness. ${ }^{4}$ A patient's dissatisfaction with information is often related to doctor-patient interaction. ${ }^{5}$ Context as well as process is important. ${ }^{6}$ Communication difficulties include lack of involvement of the patient in discussions, inadequate provision of information to the patient and family, ${ }^{7}$ and the physician's discomfort in sharing information, particularly about prognosis. ${ }^{8}$

Individualised assessment of needs and expectations is recommended as few characteristics of the patient predict his or her need for information. ${ }^{9}$ Information about prognosis should respect individual coping styles of patients and relatives ${ }^{10}$ and has been reported as important to families of patients in palliative care. ${ }^{11}$ A qualitative study of informal caregivers of patients with terminal cancer recommended an individualised approach to address needs for information about the illness and prognosis. ${ }^{12}$

\section{Box 1: Interview guide-at the start}

All interviews started with: Could you tell me something about what you know about your [your relative's] illness? Answers were usually lengthy. When necessary, prompts or direct questions were used to try to cover the points below:

- How did you find out about the illness?

- Who told you/where/who was with you/what was that like for you/was it appropriate?

- Who did you tell/not tell?

- Who first told you that you [your relative] had cancer/what do you remember about that?

- How did the doctor prepare you for bad news/how was it handled?

- Were you given enough/too much information/what else would have been helpful?

- Did you try to get information from other sources?

- Have you ever asked/been told how much time you have/should you have been given this information/did you want this information?

- Does your relative know/do you talk about it?

- Would you prefer if he/she had not been told/did not know?

- Would you prefer if you had not been told/did not know?

- [Who] do you/don't you talk to about it/why is that?

- What do you understand "palliative care" to mean?

- When did you first hear about palliative care/how was that for you

- Overall what would have made the information sharing easier for you/what would you recommend to improve the process? 


\section{Box 2: Interview guide-at the end}

These questions were asked at the end of each interview:

- Do you feel you know enough about your [his/her] condition?

- Do you think your family member knows as much as you do?

- Do you feel s/he knows enough?

(Using a scale of $1=$ extremely dissatisfied to $5=$ very satisfied):

- How satisfied are you with the way you got the initial information about your [his/her] condition?

- How satisfied are you with the way your family member got the information?

- How satisfied are you with your level of involvement in decision making?

- With your family member's level of involvement in decision making?

Other studies have focused on the information needs of patients with terminal disease and their families. ${ }^{13}{ }^{14}$ Key issues were conflict regarding disclosure of information, stress on family, feelings of loss of control, and fear of bad news. Observations in a palliative care context revealed differences in the requirements of patients and families for information about illness or prognosis. ${ }^{15}$ Requirements change over the course of the illness. ${ }^{12}{ }^{16}$ A survey of patients with advanced cancer and their carers identified pain management, fatigue, and home care resources as areas in which information was most needed. ${ }^{17}$

Few qualitative studies have included both patients in palliative care and families with specific focus on information needs. ${ }^{10}$ We elicited views of patients in palliative care and family members regarding their experiences of disclosure and information sharing during the course of the illness to identify common concerns or issues that might be used by health carers to shape and develop plans with respect to communication, with particular sensitivity to ethnic and cultural differences.

\section{Methods}

\section{Recruitment process}

Criteria for patients were a diagnosis of cancer and registration with a palliative care programme. The patient and family member had to be aged over 18 years and able to speak and understand English, without obvious cognitive impairment as judged by referring health professionals.

Access protocols were respected; the palliative care or primary nurse approached patients, who phoned researchers or gave permission to be contacted. Patients designated the family member most involved in decision making regarding their illness

Demographic information for 72 participants (patients with cancer in palliative care and relatives). Figures given and numbers (percentages) of participants, unless stated otherwise

\begin{tabular}{|c|c|c|c|c|c|}
\hline & & & & Family $n$ & bers/friends \\
\hline & All participants $(n=72)$ & Perth $(n=21)$ & Winnipeg $(n=16)$ & Perth $(n=21)$ & Winnipeg $(n=14)$ \\
\hline Men & $24(33)$ & $8(38)$ & $6(38)$ & 7 (33) & $3(21)$ \\
\hline Women & $48(67)$ & $13(62)$ & $10(63)$ & $14(67)$ & $11(79)$ \\
\hline Age (years): & & & & & \\
\hline $21-50$ & $12(17)$ & $1(5)$ & $2(13)$ & $6(29)$ & $3(21)$ \\
\hline $51-70$ & $41(57)$ & $8(38)$ & $12(75)$ & $10(48)$ & $11(79)$ \\
\hline $71-80$ & $15(21)$ & $10(48)$ & $1(6)$ & 4 (19) & 0 \\
\hline$>80$ & $4(6)$ & $2(10)$ & $1(6)$ & $1(5)$ & 0 \\
\hline Marital status: & & & & & \\
\hline Married & $52(72)$ & $12(57)$ & $11(69)$ & $17(81)$ & $12(86)$ \\
\hline Divorced & 6 (8) & $3(14)$ & 0 & $2(10)$ & 1 (7) \\
\hline Widowed & 9 (13) & $5(24)$ & $3(19)$ & $1(5)$ & 0 \\
\hline Single & $3(4)$ & $1(5)$ & $1(6)$ & $1(5)$ & 0 \\
\hline Separated & $2(3)$ & 0 & $1(6)$ & 0 & $1(7)$ \\
\hline $\begin{array}{l}\text { Mean (range) time from diagnosis to palliative care } \\
\text { (months) }{ }^{*}\end{array}$ & NA & $38.29(0-128)$ & $46.06(0-291)$ & NA & NA \\
\hline Mean (range) time between interview and death (days) $\dagger$ & NA & $122.9(11-281)$ & $78.55(16-249)$ & NA & NA \\
\hline Ethnic origin: & & & & & \\
\hline Canadian & $5(7)$ & 0 & $2(13)$ & 0 & $3(21)$ \\
\hline French & $5(7)$ & $1(5)$ & $2(13)$ & 0 & $2(14)$ \\
\hline Western European & $21(30)$ & $5(24)$ & $5(32)$ & $7(34)$ & $4(29)$ \\
\hline Eastern European & $10(14)$ & $2(10)$ & $5(9)$ & $1(5)$ & $2(14)$ \\
\hline Mohawk/Metis/Native & $3(4)$ & 0 & $1(6)$ & 0 & $2(14)$ \\
\hline Jewish & $2(3)$ & 0 & $1(6)$ & 0 & $1(7)$ \\
\hline Australian & $19(26)$ & $10(48)$ & 0 & $9(43)$ & 0 \\
\hline Brazilian & 1 (1) & 0 & 0 & $1(5)$ & 0 \\
\hline Sri Lankan & $2(3)$ & $1(5)$ & 0 & $1(5)$ & 0 \\
\hline Anglo Indian & $2(3)$ & $1(5)$ & 0 & $1(5)$ & 0 \\
\hline Chinese & $2(3)$ & $1(5)$ & 0 & $1(5)$ & 0 \\
\hline Primary language of communication: & & & & & \\
\hline English & $66(92)$ & $18(86)$ & $15(94)$ & $20(95)$ & $13(93)$ \\
\hline German & $3(4)$ & $1(5)$ & $1(6)$ & 0 & $1(7)$ \\
\hline Sri Lankan/Tamil & $1(1)$ & $1(5)$ & 0 & 0 & 0 \\
\hline Ukrainian & $1(1)$ & 0 & 0 & $1(5)$ & 0 \\
\hline Russian & 1 (1) & $1(5)$ & 0 & 0 & 0 \\
\hline
\end{tabular}

${ }^{*}$ For Perth, time between diagnosis and palliative care was <12 months in 9 (43) patients, $12-24$ months in 2 (9), and >24 months in 10 (48); for Winnipeg the figures were 7 (44), 4 (25), and 5 (32), respectively.

†Ten patients from Perth and five from Winnipeg were still alive at time of analysis. 
Box 3: Primary information source-process attributes

\section{Playing it straight}

The extent to which healthcare providers are honest and direct in conveying information:

"He is rather reluctant to commit himself to what IS wrong with you actually ... I would have sooner known right from the start and be done with it and accept it, you know what I mean?" (patient 15, Perth)

"Once you hear the word cancer ... it affects everybody in the family ... I'd rather [he'd] be straightforward and upfront. I don't like hidden stories or what else have you" (patient 17, Perth)

"I says, 'have I got much time?' And he says, 'I don't know, but there's nothing else we can give you right now.' He was honest with me, you know?" (patient 9, Winnipeg)

\section{Making it clear}

The extent to which healthcare providers convey information in ways that the patient/family can understand:

"But he doesn't know how to speak in layman's terms, and I have to say well come on, make it so I understand it" (patient 17, Perth) "I didn't know whether it [husband's strontium treatment] was going to be a danger to me ... there wasn't a lot of feedback on that at all ... It was a big worry" (relative 18, Perth)

\section{Showing you care}

The extent to which verbal and non-verbal messages conveyed by healthcare providers are given in a compassionate and empathetic manner:

"We'd ask [the doctor] a question and it was like her back was towards us. I don't know, I just didn't think she cared. I didn't really want to ask her anything... The ones at the hospital are great. They actually sit down with you and talk to you eye to eye" (relative 1, Winnipeg)

"You feel as though you are a nuisance to them, but what you want from them is [to say] come on, it's going to be hard but we are behind you and we'll give it our best shot, you know? That's what you want" (patient 3, Perth)

\section{Giving time}

The extent to which healthcare providers offer the patient and family enough time during the information discussions:

"One of them in particular is very good, and he will talk to you for quite a while and explain everything" (patient 1, Perth)

"I really appreciated, you know, the time he always took with her. .. He handled it very well, was very supportive of my mom-didn't rush us out" (relative 2, Winnipeg)

"She was very abrupt, and didn't really want to talk ... I know they're busy but they should take a little more time for their patients. And actually sit there and really talk to them" (patient 11, Winnipeg)

\section{Pacing information}

The extent to which the healthcare provider gives information in the amounts and at the rate that patients and families can assimilate:

"I always thought, why are they pushing her to her grave. For instance, her GP, when she told him that she had the cancer, the first thing he said to her, are all your affairs in order? So in other words, you don't have any time" (relative 4, Winnipeg)

"I thought, oh well, they have given up on me, I am going to die, even though I knew I was going to die ... they didn't explain fully what palliative care was" (patient 6 , Perth)

\section{Staying the course}

The extent to which messages given by the healthcare provider indicate that they will not abandon the patient/family as the illness progresses:

"He set everything up to see [specialist] ... then he said "by all means, come back ... we are not going to forget about you. We don't want you lost between the cracks,' were his exact words.

They were super, great people" (patient 5, Winnipeg)

"It was so hard because I felt a little betrayed by [the doctor]. I had trusted him and we had forged a relationship over a number of months ... he hasn't been to see me or talk to me since" (patient 14, Winnipeg) (often but not necessarily the immediate carer) and both were given separate written information; formal consent was obtained from all participants.

\section{Data collection and analysis}

We developed an interview guide to elicit detailed descriptions of participants' perceptions of their experiences of disclosure about the illness and information sharing interactions (box 1 and 2). Face-to-face, semistructured audiotaped interviews (average one hour) with patients and family members were conducted separately after a brief demographic questionnaire. No information was shared by the interviewer with the other interviewee.

One investigator (IK) conducted all interviews at the venue of choice of participants, usually the home. The investigator, a counsellor familiar with palliative care topics, was not involved in the care of any participant.

We transcribed interviews verbatim, noting emotional content. All three investigators read and independently coded transcripts using latent content analysis and constant comparison techniques. ${ }^{18}$ Unit data chunks were coded. ${ }^{19}$ Initial coding labels were written in the margins of the transcripts. The data were managed with QSR N5 (qualitative data analysis software that facilitates extensive coding, analysis, and text searches of documents). Analysis included open coding of transcripts, sorting codes with the QSR N5, multiple searches for coded excerpts, building diagrams and tables to clarify codes and levels of abstraction, and theme development. We used a consensus model, discussing and re-examining coding discrepancies to ensure consistency in application of categories. Analysis continued until no new major information on the characteristics of the category was forthcoming. We confirmed density of the identified codes using a frequency count of the coded transcripts. Definitions of emerging codes and themes were written with typical examples from the interviews to ensure clarity in communicating meaning.

We addressed recognised criteria for qualitative research: credibility, fittingness, auditability, and confirmability. ${ }^{19}$ Credibility was assessed by regular debriefing of the data collector with the team and independent coding and analysis by the investigators. Fittingness was assessed through line-by-line analysis of the interview transcripts and by providing extensive examples of the data. Detailed coding and memos written throughout the analysis enhanced auditability, enabling an examination of the "decision trail" used. Consistency of the investigators' independent coding was examined and confirmed.

\section{Participants}

In depth interviewing beyond a small number does not result in any new information and leads to redundancy in the data. ${ }^{19} \mathrm{We}$ determined the number required to reach redundancy in Perth and then interviewed a similar number in Winnipeg. The table gives details of the participants. We interviewed 72 participants: 21 patients (16 home-hospice and five inpatients) and 21 relatives in Perth, and 16 patients (14 home palliative care and two inpatients) and 14 relatives (two were later unavailable) in Winnipeg.

\section{Results}

All participants, regardless of ethnic background, described the process of obtaining information about the illness during the course of the disease in considerable detail and with notable consistency. Information was received through two major sources: primary (including primary and specialist health providers) and secondary (family, friends, literature, internet, 
support groups, complementary therapists). Primary information transfer occurred in response to the initial diagnosis, new information about the illness, or change in the patient's condition. The primary source was the main focus of the interviews and analysis.

The two major themes we identified were process and content. The process of communication was the central and critical feature of the information sharing experience and encompassed how the content was perceived. Other related themes were the role and purpose of information gathering from secondary sources and the changes in needs for information.

\section{Process}

Many participants reported dissatisfaction with the communication process, especially at disclosure of the initial diagnosis. Six attributes were identified to be important in communicating information: playing it straight, staying the course, giving time, showing you care, making it clear, and pacing information (see box 3).

Information transfer occurs repeatedly during the course of the illness; in the earlier phases surgeons and oncologists were more apparent as information providers whereas in the terminal stage it was the palliative care team. Each new phase required the same sensitivity to the process attributes to allow integration of new facts. Understanding of the implications of one phase of the illness did not necessarily carry over to the next phase. The way in which previous information had been provided could influence subsequent responses. If trust was compromised in the initial disclosure, it often remained an issue at subsequent stages, even if the health carers had changed.

\section{Content}

The two most important content areas were prognosis and hope.

Prognosis-Participants described their need for information about prognosis, its accuracy, and the importance of being able to refine their understanding about prognosis as the disease progressed. Many reported that it enhanced communication with family. The timing of disclosure about prognosis was important. Although most patients and families requested this information as soon as or shortly after diagnosis was confirmed, many reported that they were distressed at how it was given. Some stated the information had been given too soon or when they hadn't asked for it. Participants sometimes verbalised ambiguity: they wanted to be told but they did not want to know. Often the exact words used by doctors were vividly remembered. Participants were distressed when information about prognosis was perceived as vague or inaccurate, was presented along with conflicting or inconsistent information, or was given by someone not perceived to be an expert or directly in charge of the patient. Evasiveness was often perceived as unhelpful (box 4).

Hope-The second most important content area was the provision of hope and the need for hopeful messages at all stages, described as a possibility for cure or longer life or related to short term visions of the future or continued care or an indication that the health professionals are not giving up. Patients expressed a continuing need for hope even when they knew and accepted that they were in the terminal stages of disease and had a limited life expectancy. Even in the end stages, patients and families still wanted the door to be left open for the possibility of a miracle; many expressed a compartmentalised awareness, simultaneously acknowledging the terminal nature of the illness, while retaining a need and sense of hope. To have hope dashed by a rushed or insensitive health carer was experienced extremely negatively. Two dimensions of hope were described: patient/family orienta-

\section{Box 4: Key elements of information content related to} prognosis and exemplars

\section{Expert disclosure}

The need for prognostic information to be given by the health provider perceived to be an expert:

"She wasn't a cancer doctor, so she shouldn't have done it in the first place... I know she had been treating him for the last 10 days, but I think we should have been told by somebody that could have given us a little bit more information on what actually was going to happen" (relative 14, Perth)

"I was annoyed that he [admitting doctor] was just giving a prognosis from his point of view-[but] the other doctor would have had a good knowledge of the prognosis from discussing it with the oncologist, so what she said we believed" (relative 22, Perth)

\section{Specificity of prognostic information}

The need for honesty and respect for the level of detail wanted by the patient/family:

"I asked how much time and he said he couldn't tell me because he wasn't God ... I didn't care for that answer very much. I thought maybe he could be a little more specific. Sometimes it seems that the information is strictly for the medical staff and not for the people" (patient 6, Winnipeg)

"Doctors shouldn't say-I have noticed a lot of it that doctors tell patients they are not going to live very long. But they go on years afterwards. Quite a lot" (patient 1, Perth)

"I don't want to know when. I would like to go to sleep and don't wake up, eh, that would be the best thing. I'm not scared, but if somebody is going to say, you've got two days, four days ... I don't want that" (patient 12, Winnipeg)

\section{Illusion and need for predictability}

The need for control as a means of coping that may or may not be met by prognostic information:

"It's important to know what's going on. If it's a short time, well, let us know so we can make some plans and look at making the last little bit as good as possible" (relative 10, Winnipeg)

"You can deal with things a lot easier I think if you know what's going on than if you don't know what's going on, you know. I can talk about it to them [the family]" (patient 3, Winnipeg)

"I would have been dead cross if I hadn't found out, [because] you start to think, are my affairs in order, mine weren't. And it has taken me almost till now to sort of get things all organised" (patient 7, Perth)

"It was almost a relief, I think, to find out what it was-I'm not frightened of dying ... I also had a sense of relief when it didn't seem that I was going to be hanging around too long exhausting my children, which I am aware of the fact that it will do. But I haven't become depressed about it or anything" (patient 21, Perth)

\section{Individual timing}

A need to assess the readiness of patient/family to hear information about prognosis:

"Like if they would have told her that in the beginning, they would have given her a time frame, I think that would have been harder. I think now that she has dealt with many things, come to terms with a lot of things-this is just the final part of that whole circle" (relative 2, Winnipeg)

"I don't want to know about [palliative care] at the moment. I sort of live in hope and the chemotherapy has done wonders for her . .. there is probably a lot they could do for my mother but I sort of associate palliative care with the dying process ... That's why I get upset to even think about it" (relative 1, Perth)

"The prognosis has sort of changed, so with the change in prognosis then you get a change in what kind of information you need to have. Now I get anxious as to what is going to happen to me as I get worse" (patient 16, Winnipeg) 
tions to hope (box 5) and messages from the healthcare providers supporting hope (box 6).

\section{Information gathering from secondary sources}

Most patients and especially family members obtained additional information from the internet, friends, support groups, books, or second opinions from other health providers, conventional or alternative. There was some evidence that this information was of greater importance in instances where communication with health carers had not been perceived as sensitive or satisfactory, or both. Secondary sources expanded information, which decreased uncertainty, allowed the search for hopeful alternatives (treatment options or alternative therapies), gave some sense of control, and helped to make or confirm decisions about care, treatment, or lifestyle choices (box 7).

\section{Changes and divergence of information needs}

The needs of patients and families were similar but diverged somewhat as the illness progressed. Many patients reported not wanting as much detail about prognosis as they had asked for initially. In early stages families and patients talked to the health carers together. In later stages family members often talked to them alone, often at the patient's request, and did not confirm the patient's exact state of knowledge. They often assumed less awareness in the patient than was evident in our interviews. Patients and family members did not talk as openly and sheltered each other from knowledge (see box 7). All reported that they complied with their relative's requests for the amount of information they wanted. Patients focused more on daily living and concerns about managing symptoms; families were more concerned with prognosis and details related to care.

\section{Discussion}

In this study of patients with terminal cancer and their relatives the need for sensitivity and respect for individual wishes in the communication process emerged as a central theme in the interviews. While this was especially important at the time of the initial disclosure, it recurred at all the different stages of information provision during the illness and affected the way in which content was perceived. The content needs most important to families and patients related to prognosis and hope. Open communication regarding all aspects of the illness and its progress was reported as desirable by almost all participants,

Box 5: Patient/family orientations to hope: perspectives of patients and families

Needing to believe in a miracle

Patient's or family member's continuing need to believe that the patient will not die:

"I would like to know the truth, but there is a way between saying 'Well, you have cancer of the cervix and it's incurable', instead of, 'We'll do our best ... and there are miracles in the world' [a miracle] still can happen ... I'm still here [laughs]" (patient 15, Perth)

\section{Living parallel realities}

The capacity to acknowledge both the terminal nature of the illness and still hope for a cure/remission:

"Well, I feel invincible, even though I know it's growing again I still feel invincible but I still know that I'm going to die ... I manage to have these two things in my head at the same time, right and left" (patient 14, Perth)

"He knows the extent of his illness, but when he's talking to me, [it's as if] he's going to be here forever" (relative 18, Perth) regardless of cultural backgrounds. All patients said they wanted to know the diagnosis of their illness. With two exceptions (in patients who shared information only in later stages) they thought it important that information was fully shared with their families during all of the illness. All family members thought it was important for the patient to know the diagnosis. Almost all patients wanted to know their prognosis, and family members respected their wish to know or not, although some would have wanted to protect the patient from details regarding prognosis. No family members had requested that the patient was not fully informed. Most patients wanted their family member present when they met health carers, although a small number expressed a desire to be the first to know or to control how much or when the family member should be told.

\section{Box 6: Supporting hope: words and approaches to communication that respect the need for hope}

\section{Leaving the door open}

The extent to which the health professional communicates in ways to allow preservation of hope:

"We want the information but there has to be a sliver of hope left ... Her oncologist said to her, 'I want to continue with the treatment, there's a $30 \%$ chance here.' He has not ever said a 30\% chance of what or for how long, but just hearing that has been what has kept her quality of life for these past six months so much more bearable and better than without hearing that" (relative 14, Winnipeg)

"I don't mind what I hear, so long as there is a little light at the end of the tunnel you know what I mean? ... a little bit of hope there, yes" (patient 16, Perth)

\section{Retaining professional honesty}

The need for health professionals to acknowledge their own difficulties in giving a hopeful prognosis:

"He sort of waffled around it ... I didn't like that" (patient 2, Perth)

"[The doctors] said I probably only have months to live... And she said nobody can tell how long you have. But just to get everything in order. I think it was the right thing to do" (patient 10 , Winnipeg)

"[The doctor] is not God so he can't say exactly you have six months. I think he gave away hope. In dad's eyes I can see that he lost a bit of hope" (relative 12, Perth)

\section{Pacing the move towards palliative care}

The need to present information about palliative care at a rate that patient/families can assimilate:

"And she said I have come to talk to you about palliative care, and he just went into an absolute heap. And of course, that word when you say 'palliative care' he immediately thought death in three months. He just went into absolute shock-burst into tears .. It was too soon" (relative 6 , Perth)

"[The doctor said] we should prepare something in palliative care. [I felt that] he wrote me off, so I went for another doctor" (patient 15, Winnipeg)

\section{Respecting alternative paths}

The need to allow patient/families to explore other possibilities for hope:

"He advised me not to even bother going for treatments. We were talking about maybe even going into alternative medicine. And he says, well don't bother with that, it's just a waste" (patient 5, Winnipeg)

"I go to the library over here, on the internet, and I also get a lot of information from my brother. I take a lot of vitamins and stuff like that. I asked [the doctor] at the first if it was all right if I took them. And he said, 'That's fine, keep doing it, don't stop'.' (patient 11 , Winnipeg) 


\section{Box 7: Information}

\section{Accessing secondary sources}

"The doctors don't have time to sit there and explain every treatment that's available so, I believe, if you want to be informed you've got to do your own homework, yes." (relative 12,Perth)

"So she [daughter] knows that by going on the internet she's got the actual information we're supposed to have" (patient 2, Winnipeg)

"In the meantime, my dear friends have all got together and said you've got to go the herbal way go and see this dear herbal biologist ... he's put me on all this stuff-but it hasn't done much [laughter]" (patient 17, Perth)

"One of my son's best friends is a GP ... And we would sort of check back with him, are we getting the right sort of stuff. We downloaded from the internet information on bisphosphonate" (patient 2, Perth)

\section{Changes and divergence in need for information}

"At the beginning I needed tons (of information). And then at one point I just got tired, you know .... And right now I believe I have plenty of information and I would just like to be left to my own devices for a while" (patient 14, Winnipeg)

"On one hand I would like to [know my prognosis now] ... if I know, I can tell myself, so that's it. But I'm not so interested any more." [It has changed?] "Yes" (patient 15, Winnipeg)

"What else is there to know, really? There's nothing more to know. I feel, anyway" (patient 1, Winnipeg)

"What good does it do to know any more at our stage, ah ... I guess what I concern myself about is, will there be a huge amount of pain and discomfort and suffering as we get near the end, you know, and that sort of thing ... I'm not fully sure how that will unfold" (relative 16, Winnipeg)

"Now, I guess I would get anxious as to what is going to happen to me as I get worse, and whether I can stay at home and be here, or whether I would have to go to hospital" (patient 16, Winnipeg)

Changes in communication patterns between family members Family and patients stop communicating openly:

Daughter: "I don't believe she has a lot of time left. No one will actually tell me which is in some ways good. I wouldn't tell, I don't think mum needs to know. She seems to think she has a year or more" (relative 19, Perth)

Contrast with mother:

"He didn't tell me how long I had though ... can't get them to tell me that. [Laughter] But anyway it's been quite exciting since ... getting everything done-wills made and all sort of things ... The way it's deteriorated since [previous month] I sort of feel that I want to be ready" (patient 19, Perth)

Daughter: "The conversation's pretty open between us. [A few moments later in interview] I believe that she doesn't

acknowledge the extent that the changes are happening" (relative 21, Perth)

Mother: "They [family] know anything I know ... what I haven't done is asked them, you know, what's going to happen ... I think they've taken it, in a sense, a lot harder than me ... all I'm going to have to do is die. They've got to watch me die and then get on without me" (Perth 21P)

\section{Role of information}

Participants described information as a mechanism that enhanced decision making and keeping some control. A perception of insufficient information was reported to add stress, frustration, and uncertainty. Most reported that they were ultimately satisfied with the amount of information they had, although most had supplemented it through secondary sources. Further research on the role and impact of secondary information sources would be of interest.

\section{What is already known on this topic}

Communication of prognosis to patients with cancer is a sensitive issue

Patients' needs for information should be individually assessed

Few qualitative studies have been done to assess needs of patients and their relatives

\section{What this study adds}

The process of communication regarding diagnosis and prognosis affects how information is perceived

Six attributes were identified as necessary for sensitive information sharing: playing it straight, staying the course, giving time, showing you care, making it clear, and pacing information

\section{Limitations}

We had hoped to target participants of specific ethnic-cultural backgrounds, expecting to find considerable cultural differences in the desire for openness in information sharing as reported by others. ${ }^{21}$ Although participants came from various cultural backgrounds (22 had been born outside of Australia or Canada), access protocols dictated a large measure of self selection, so it may be assumed that patients in families experiencing conflict in regards to the sharing of information would not volunteer to participate. A more narrowly targeted ethnic group would probably lead to different observations and might show different preferences.

Integration of information was an ongoing cyclical process; it takes time to integrate prognostic information. ${ }^{16}$ Others have noted that some patients with advanced cancer may behave as though nothing is wrong despite being fully informed about prognosis, ${ }^{22}$ although this was evident only in an attenuated form in this study.

Prognostic information needs to be individualised. ${ }^{5}{ }^{10}$ Contrary to findings in another study, ${ }^{23}$ awareness of prognosis was remarkably similar between patients and relatives, possibly because most were in a close relationship (over half were spouses and nearly a third were daughters). This aspect needs further study. The importance of hope is consistent with other findings. ${ }^{10}$ Hope and need for hope was expressed in different ways, even when participants were fully aware of the terminal stage, and health carers can convey hopeful messages at any stage.

Information transfer is not a discrete event related to diagnosis or the discussion of specific issues. The consistency of the comments regarding unsatisfactory perceptions of this experience indicates the need for further awareness of the individual needs of patients and families by health carers. Other studies confirm that needs for information vary at different stages. ${ }^{24} \mathrm{We}$ have provided a framework for understanding the overarching importance of process in communication between health professionals and patients and families in the context of a terminal cancer. Six critical attributes of good communication are important: playing it straight, staying the course, giving time, showing you care, making it clear, and pacing information. They affect the quality of the relationship between health professionals and patients and families and should be emphasised in the teaching of communication skills. 
We gratefully acknowledge all the participants interviewed for this study, and thank Gill Lewin and the Silver Chain Home Hospice, Geoff Duggan and Annette Cummins at the Cottage Hospice, and palliative care coordinators in Winnipeg, especially Dennis St Laurent, for their help in recruiting patients. Marcelo Garcia sparked off the initial idea for the need for this study.

Contributors: PK and IK had the initial idea for the study. LJK provided the conceptual framework and gave feedback at each stage of the study. All authors read, coded, and analysed transcripts. IK conducted the interviews, collated the analyses, and wrote the study. PK undertook the initial literature review and is guarantor.

Funding: Centre for Bioethics, University of Manitoba.

Competing interests: None declared.

Ethical approval: Obtained from institutions involved (Cancer Foundation and Edith Cowan University in Perth, Australia, and University of Manitoba and Riverview Health Centre in Winnipeg, Canada).

1 Schouwstra J, Van der Blink JW. Communication in the cancer patient: the Dutch situation. Ann NY Acad Sci 1997;809:422-39.

2 Bruera E, Neumann CM, Mazzocato C, Stiefel, Sala R. Attitudes and beliefs of palliative care physicians regarding communication with terminally ill cancer patients. Palliat Med 2000;14:287-98.

3 Crawley LM, Marshall PA, Lo B, Koenig BA. Strategies for culturally effective end-of-life care. Ann Intern Med 2002;136:673-9.

4 Baile WF, Buckman R, Lenzi R, Glober G, Beale EA, Kudelka AP. SPIKES-a six-step protocol for delivering bad news: application to the patient with cancer. Oncologist 2000;5:302-11.

5 McPherson CJ, Higginson IJ, Hearn J. Effective methods of giving information in can cer: a systematic literature review of randomized controlled trials. J Pub Health 2001;23:227-34.

6 Ptacek JT, Eberhardt TL. Breaking bad news. A review of literature. JAMA 1996;276:496-502.

7 Stewart MA. Effective physician-patient communication and health outcomes: a review CMAJ 1995; 152:1423-33.

8 Christakis, NA. Death foretold. Chicago: University of Chicago Press, 1999.

9 Kutner JS, Steiner JF, Corbett KK, Jahnigen DW, Barton PL. Information needs in terKutner JS, Steiner JF, Corbett KK, Jahnigen
minal care. Soc Sci Med 1999;48:1341-52

10 Davies E, Higginson IJ. Communication, information and support for adults with malignant cerebral glioma: a systematic literature review. Support Care Cancer 2003;11:21-9.
11 Vachon ML, Kristjanson L, Higginson I. Psychosocial issues in palliative care: the patient, the family, and the process and outcome of care. J Pain Symptom Manage $1995 ; 10 ; 142-50$

12 Rose KE. A qualitative analysis of the information needs of informal carers of terminally ill cancer patients. J Clin Nurs 1999;8:81-8.

13 Mclllmurray MB,Thomas C, Francis B, Morris S, Soothill K, Al-Hamad A. The psychosocial needs of cancer patients: findings from an observational study. Eur J Cancer Care (Eng) 2001;10:261-9.

14 Mystakidou K, Parpa E, Tsilika E, Kalaidopoulou O, Vlahos L. The families' evaluation on management, care and disclosure for terminal stage cancer patients. BMC Palliat Care 2002;1:3.

15 Code K, Paul J. Caring until the end. Austr Nurs J 1997;5:20-3.

16 Faulkner A, Maguire P. Talking to cancer patients and their relatives. Oxford: Oxford University Press, 1994.

17 Wong RKS, Franssen E, Szumacher E, Connolly R, Evans M, Page B, et al. What do patients living with advanced cancer and their carers want to know? A needs assessment. Support Care Cancer 2002;10:408-15.

18 Glaser BG, Strauss AL. The discovery of grounded theory: strategies for qualitative research. New York: Adline Press, 1967.

19 Lincoln YS, Guba EG. Naturalistic inquiry. Beverly Hills: Sage, 1985.

20 Altheide DL, Johnson JM. Criterion for assessing interpretive validity in qualitative research. In: Denzin N, Lincoln Y, eds. Handbook of qualitative research. London: Sage Publishers, 1994:485-99.

21 Surbone A. Truth telling to the patient. JAMA 1992;268:1661-2.

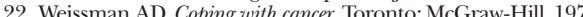

Hinton J. The progress of awareness and acceptance of dying assessed in cancer patients and their caring relatives. Palliat Med 1999;13:19-35.

24 Butow PN, Maclean M, Dunn SM, Tattersall MH, Boyer MJ. The dynamics of change: cancer patients' preferences for information, involvement and support. Ann Oncol 1997;8:821-4.

(Accepted 28 March 2004)

doi $10.1136 /$ bmj. .38103 .423576 .55

Island Medical Program, Universities of Victoria and British Columbia, Victoria, BC, Canada V8N 1V7

Peter Kirk clinical professor (family medicine and palliative care)

Victoria Hospice Society,Victoria, BC, Canada V8R 1J8

Ingrid Kirk educator and hospice volunteer

School of Nursing and Public Health, Edith Cowan University, Perth, WA 6018,

Australia

Linda J Kristjanson professor

Correspondence to: P Kirk clincoor@uvic.ca 